\title{
A reforma gerencial brasileira em questão: contribuições para um projeto em construção
}

Vanessa Brulon; Pierre Obayon e Gerson Rosenberg

\section{Introdução}

Devido à importância do papel desempenhado pela administração pública, sua forma de se organizar passou por mudanças ao longo dos anos em busca de aprimoramento. As críticas aos modelos adotados deram origem a alguns processos de reforma que se disseminaram entre muitos países. O Brasil também sofreu o reflexo desse processo.

Os Estados nacionais, que hoje se encontram entre modelos burocráticos e gerenciais, variando de acordo com o país, até o início do século XX seguiam um modelo patrimonial de administração, caracterizado, principalmente, pela ausência de uma clara separação entre patrimônio público e patrimônio privado (Bresser-Pereira, 2009). Schwartzman (2006) explica que o termo "patrimonialismo" é originado nos trabalhos de Weber que, segundo o autor, o usou para se referir à forma de dominação tradicional, que está baseada na crença nas tradições, e é a partir dela que se torna legítima (Weber, 2009). 
Assim, para Weber (2009), toda dominação tradicional tende ao patrimonialismo. Entretanto, com críticas fortes ao modelo, como o autoritarismo, a corrupção e o nepotismo, esse acabou por ser substituído pelo modelo burocrático, na década de 1930, no Brasil.

Para que pudesse atender ao seu novo papel de indutor do desenvolvimento econômico, o Estado precisou se transformar, por meio da racionalização burocrática do serviço público (CostA, 2008a). Esta transformação envolveu a padronização, normatização e implementação de mecanismos de controle, como explica Costa (2008a), em um processo conhecido como reforma burocrática da administração pública. A administração pública adota, assim, uma forma racional-legal de dominação, descrita por Weber (2009) como aquela que se legitima a partir da crença em regras e normas. Entretanto, o modelo burocrático também é alvo de críticas, na medida em que sua rigidez e inflexibilidade tornam a administração pública ineficiente.

Diante das severas críticas direcionadas ao modelo burocrático de administração, adotado pela administração pública brasileira até o fim do século XX, há uma disseminação das reformas gerenciais, impulsionada principalmente pelo movimento da New Public Management. Caracterizada principalmente pelo foco em resultados, esta nova "onda" de reformas foi posta em prática em muitos países do mundo, entre os quais se inclui o Brasil.

Essa disseminação foi impulsionada principalmente por um contexto de crise do Estado, que leva à necessidade de reconstruí-lo, por meio de processos de reforma (Bresser-Pereira, 2001). Outro fator importante, que levou à tentativa de adoção do modelo gerencial pelos países emergentes, é o Consenso de Washington. Paes de Paula (2005a) ressalta a importância da reunião e explica que, a partir dela, houve consenso entre os presentes, baseado na reforma posta em prática no Reino Unido, de que os países emergentes deveriam adotar as reformas orientadas para o mercado, em busca do desenvolvimento. Esse fator facilita a aceitação da reforma gerencial como um parâmetro também para os países da América Latina.

No Brasil, apesar de a reforma gerencial não ter sido concluída, o modelo gerencial de administração assume papel importante na administração pública hodierna. Pode-se observar no País forte tendência à adoção de reformas administrativas que seguem esse modelo. Um exemplo é o programa Choque de Gestão, posto em prática no Estado de Minas Gerais, durante o governo de Aécio Neves. Tal programa acabou se disseminando para outros estados do Brasil e é considerado atualmente modelo de sucesso a ser seguido.

Em decorrência da forte visão positiva associada à reforma gerencial no País, o movimento gerencialista se dissemina e tenta fundar uma nova administração pública. Entretanto, como afirma Paes de Paula (2005b, p. 47), "esse é ainda um projeto em construção". Como um projeto inacabado, segundo Paes de Paula (2005b), a nova administração pública está sempre sendo reinventada, e, por isso, reflexões a respeito dos processos de reforma que lhe dão base sempre se fazem atuais. Indo ao encontro de Paes de Paula (2005b), e visando trazer possíveis contribuições para a construção de uma nova administração pública brasileira, o presente trabalho tem por objetivo identificar as possíveis vulnerabilidades presentes no processo de reforma gerencial no Brasil. 


\section{A reforma gerencial no mundo}

Apesar de apresentar algumas variações nos diferentes países em que foi adotado, o modelo gerencial possui características que podem ser generalizadas. Secchi (2009), por exemplo, identifica como valores da administração pública gerencial a produtividade, a descentralização, a eficiência na prestação de serviços, a accountability, entre outros. Indo ao encontro de Secchi (2009), o Clad (1998) defende que as principais características do modelo gerencial são: a profissionalização da alta burocracia, a transparência da administração pública, a descentralização da execução dos serviços públicos, desconcentração organizacional nas atividades exclusivas do Estado, e orientação para o controle de resultados. Características semelhantes estão presentes na caracterização genérica dos modelos gerenciais apresentada por Holmes e Shand (1995, apud MARTins, 1997), que também destacam a orientação para resultados, a descentralização, a flexibilização, a transparência, entre outras. Modesto (1997) acrescenta às características apresentadas por esses autores o estímulo à privatização, a capacitação de pessoal dirigente, a criação de carreiras específicas para altos gestores, a elaboração do conceito de planejamento estratégico etc.

O modelo gerencial tem, assim, sua inspiração nas transformações do setor privado, que buscam a flexibilização da gestão, a redução dos níveis hierárquicos e o aumento da autonomia dos gerentes para a tomada de decisão (CLAD, 1998). Mesmo que possa ser caracterizada de forma genérica, a experiência internacional possibilita que se observem diferentes enfoques teóricos, medidas de reforma, estratégias, não havendo reforma que sirva de modelo
(Fleury, 2001). Neste sentido, O Clad (1998, p. 125) também defende que, apesar das características comuns, "O modelo gerencial deve, impreterivelmente, adequarse ao contexto político-democrático no qual está inserido o setor público".

Ainda que não exista processo de reforma que seja sempre tomado como referência e adotado como modelo a ser seguido, os países que deram início a esse processo são citados com frequência

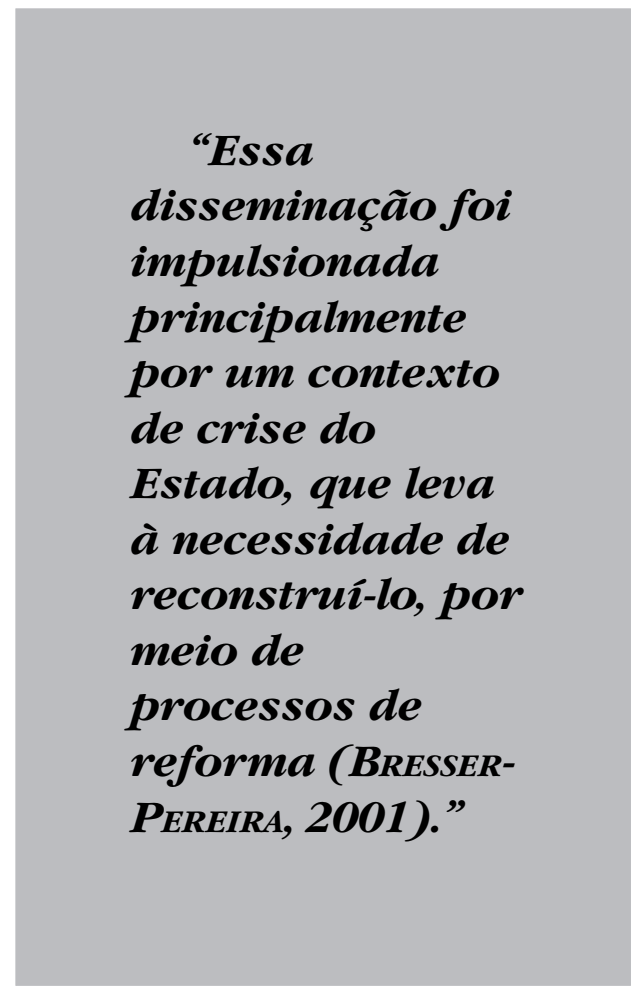

como exemplo, e exerceram forte influência nas reformas que se seguiram nos demais países. Como mostra Martins (1997), as reformas gerenciais surgem em resposta à crise do Estado na década de 1970, e começam a ser adotadas a partir da década de 1980 por países como Reino Unido e Estados Unidos. Como pioneiros na adoção do modelo gerencial de 
administração pública, suas reformas servem de referência.

O Reino Unido, primeiro país do mundo a adotar o modelo gerencial, teve seu processo de reforma posto em prática durante o governo de Margaret Thatcher, na década de 1980. Pollitt (1996), a partir de sua análise da reforma gerencial no Reino Unido, defende que ela pode ser dividida em três fases: de 1979 a 1982, em que o foco estava na economia, com o corte dos gastos totais; de 1982 até o fim da década de 1980, em que o foco torna-se a eficiência, sendo marcado pelo aumento das privatizações; e a partir de 1987, fase mais radical, que é marcada por uma série de reformas em diferentes setores do serviço público.

Ao longo dessa trajetória, a reforma gerencial do Reino Unido, como mostraram Macedo e Alves (1997), adotou algumas formas inovadoras de gestão. A primeira delas, citada por Macedo e Alves (1997, p. 65), são os chamados “escrutínios de Rayner", que os autores caracterizam como "pequenos grupos formados por funcionários departamentais e assessorados por um grupo central (unidade de eficiência); esse, por sua vez, ligado diretamente ao gabinete do primeiro-ministro e chefiado pelo próprio Rayner", que realizam avaliações departamentais.

Uma segunda forma inovadora de gestão, citada pelos autores, é o desenvolvimento de sistemas de informações gerenciais, que tem como principal exemplo o Management Information System for Ministers (Minis). Atuando como um escrutínio permanente, o Minis permitia a revisão detalhada das atividades do departamento, bem como das necessidades de recursos humanos (Macedo E Alves, 1997). Os Citizen's Charter também são outra inovação, que podem ser entendidos como documentos nos quais estão especificados os objetivos e normas de cada serviço público, bem como os recursos disponíveis para sua execução e seus responsáveis, representando uma abertura em relação ao modelo burocrático (Macedo e Alves, 1997).

Além dessas inovações, Tatcher implementou amplo processo de privatização, operado principalmente pela venda de ativos, como explicam Macedo e Alves (1997). Os autores ressaltam, ainda, a importância do Next Steps, programa implantado em 1988, com o objetivo de dar continuidade ao aumento da eficiência no setor público. Com vistas a reduzir os gastos públicos, houve um corte no quadro de pessoal, bem como a busca por um novo modelo de determinação de pagamentos (Macedo e Alves, 1997).

No caso dos Estados Unidos, onde o processo ocorreu posteriormente, durante o governo Reagan, este foi marcado pelo movimento "Reinventando o governo", de Osborne e Gaebler (1994, p. 338). No livro que deu origem ao movimento, Osborne e Gaebler (1994) apresentam 10 princípios que, segundo os autores, quando aplicados a qualquer organização, "têm o poder de liberar novas formas de pensar - e de agir", modificando o modelo básico de governo, adotado até então. Assim, os autores defendem que seja adotado um novo paradigma, que possibilite uma nova forma de pensar o governo. Segundo Kettl (2000), o movimento buscou transformar o governo dos EUA, em um curto período de tempo, para que adotasse o foco no cliente, aumentasse a produtividade e reduzisse os custos. Diferentemente do Reino Unido, nos EUA houve poucas privatizações, com predomínio maior de parcerias público-privadas (KETTL, 2000). 
É dentro desse contexto que surge o movimento da New Public Management (NPM), principalmente a partir das reformas ocorridas em países como o Reino Unido, EUA, Nova Zelândia e Austrália. A este respeito, Barzelay (2001) explica que o termo New Public Management expressa a ideia de um fluxo cumulativo de decisões políticas que levaram a mudanças na governança e no gerenciamento do setor estatal desses países. A NPM, segundo o autor, refere-se ao desenvolvimento de práticas de rotinas inovadoras, voltadas para o aumento do desempenho. Conforme Osmond e Löffler (1999), a NPM levou a uma visão mais econômica e gerencial da administração pública. Page (2005) complementa essa ideia, ao afirmar que a NPM apresenta como algumas das suas características básicas a busca pelo aumento da performance governamental, descentralização, mecanismos de mercado e accountabillity. Embora possam ser citadas características básicas da NPM, Ormond e Löffler (1999) destacam que o termo assume diversos significados em contextos diferentes.

Seguindo o exemplo dos países pioneiros, como Reino Unido e EUA, outros países guiaram-se pela lógica da NPM, ao implementar seus processos de reforma. $\mathrm{Na}$ América Latina, esse modelo também foi adotado, com muitas tentativas frustradas, como mostra Bresser-Pereira (2002) em sua análise sobre a NPM neste continente. Conforme o autor, os países latino-americanos que foram mais adiante no processo de reforma gerencial foram o Brasil e o Chile.

\section{A reforma gerencial no Brasil}

Assim como em outros países do mundo, no fim do século XX o Brasil passou por um período que foi considerado como de crise do Estado burocrático, que levou à sensação de uma necessidade de reformá-lo e reconstruí-lo. Ainda que apresente características em comum com as demais reformas ocorridas em várias partes do mundo, a reforma gerencial posta em prática no Brasil também tem suas peculiaridades, que a distinguem das demais.

A administração pública no Brasil evoluiu historicamente por meio de três modelos básicos: a administração pública patrimonialista, a administração burocrática e a administração gerencial. Estas três formas se sucederam no tempo, sem que qualquer uma delas tenha sido inteiramente abandonada.

Analisando a evolução histórica da administração pública brasileira, pode-se verificar que o Brasil passou pelo patrimonialismo, atravessou a fase burocrática, e, após a Reforma Administrativa do Aparelho do Estado de 1995, achou-se pronto legalmente para ingressar na administração gerencial. Entretanto, antes de ingressar no processo de reforma gerencial, o Brasil passou por pequenas reformas administrativas que lhe deram base. Para melhor analisá-las, pode-se dividi-las em cinco períodos distintos, como descritos no quadro 1.

No primeiro período que compreende de 1930 a 1945, com uma extensão até 1963, existiram estudos não implementados. Houve um esforço de inovação e renovação do aparato governamental fundamentado no modelo burocrático, introduzido com a criação do Departamento Administrativo do Serviço Público (Dasp) em 1936.

O segundo período, de 1964 a 1985, é justificado pela necessidade de maior agilidade e flexibilidade para atender às demandas de um Estado desenvolvimentista. 


\section{Quadro 1: As principais reformas administrativas do Estado}

\begin{tabular}{|c|c|c|}
\hline Reforma & Periodo & Caracteristicas Principais \\
\hline $\begin{array}{l}\text { Criaçào do } \\
\text { DASP }\end{array}$ & 1930-1945 & $\begin{array}{l}\text { Implantaçào impositiva do modelo burocrático. Racionalizaçào dos métodos } \\
\text { administrativos. Criou o sistema de mérito na administraçâo, orçamento usado } \\
\text { como plano administrativo e revisão das estruturas. }\end{array}$ \\
\hline $\begin{array}{l}\text { DecretoLei } \\
\text { n"}^{\text {"} 200-} \\
1967 / 69\end{array}$ & $1964-1985$ & $\begin{array}{l}\text { Descentralizaçâo institucional (administraçâo direta e indireta), transferências de } \\
\text { atividades para o setor privado, substituição de funcionários estatutários por } \\
\text { celetistas, redução da atuaçâo do Dasp. }\end{array}$ \\
\hline $\begin{array}{l}\text { Extinção do } \\
\text { DASP }\end{array}$ & 1986-1988 & $\begin{array}{l}\text { Extinção dó Dasp e criação da Secretaria de Administração Pública da Présidêncià } \\
\text { da República (Sedap), em } 1986 \text {. A Reforma da Administraçâo Pública, aprovada pelo } \\
\text { Presidente Jose Sarney, em 1986, teve como princípios: racionalizaçâo e contençào } \\
\text { de gastos públicos, formulação de nova política de recursos humanos e racionali- } \\
\text { zaçăo da estrutura da administraçâo federal. }\end{array}$ \\
\hline $\begin{array}{l}\text { Constituição } \\
\text { de } 1988\left(^{\circ}\right)\end{array}$ & $1988-1995$ & $\begin{array}{l}\text { Instauraçào de um Regime Jurídico Único para todos os servidores públicos, esta- } \\
\text { belecendo a relaçáo de trabalho, estabilidade rigida dos funcionârios, eliminou } \\
\text { toda autonomia das fundaçôes e autarquias, criou um sistema rígido de concursos, } \\
\text { inviabilizando uma parte das novas vagas para os servidores existentes. }\end{array}$ \\
\hline $\begin{array}{l}\text { Plano } \\
\text { Diretor da } \\
\text { Reforma do } \\
\text { Aparelho } \\
\text { do Estado e } \\
\text { Emenda } \\
\text { Constitu- } \\
\text { cional n } \\
\text { 19/98 }\end{array}$ & Após 1995 & 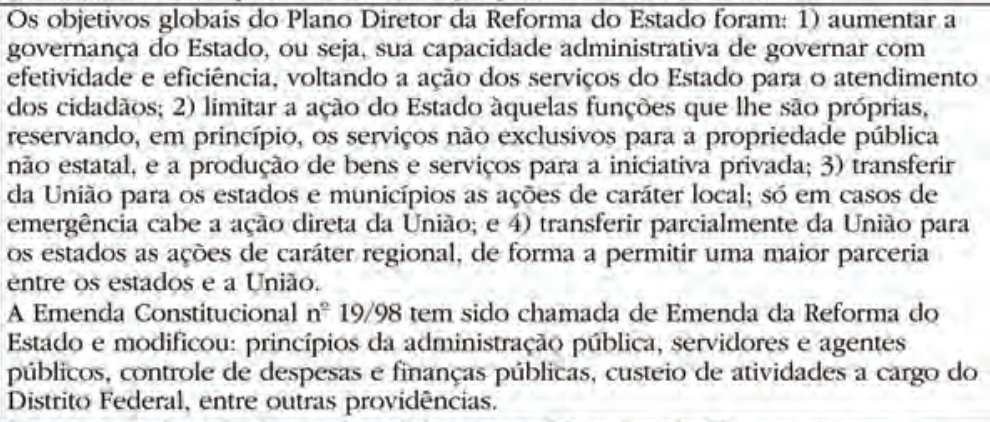 \\
\hline $\begin{array}{l}\text { Extinçào } \\
\text { do Mare }\end{array}$ & 1999 & $\begin{array}{l}\text { Passa a coordenação da gestão pública para o Ministério do Planejamento, que, } \\
\text { por sua vez amplia a sua ação de planejamento, redefinindo-se como Ministério de } \\
\text { Planejamento, Orçamento e Gestão. }\end{array}$ \\
\hline
\end{tabular}

Fonte: Elaboração própria adaptada de Marcelino (1988). ${ }^{1}$

O terceiro período, iniciado em 1986 e finalizado em 1988, foi marcado pela demanda da sociedade por contenção de gastos governamentais e, ao mesmo tempo, pela necessidade de se criar mecanismos e instrumentos que permitissem uma gestão pública eficaz e eficiente.

O quarto período é caracterizado pela Constituição de 1988, que, após o regime autoritário, esmerou-se na abundância de normas, buscando assegurar a garantia de direitos dos cidadãos e limitar a amplitude de poderes do Estado, resultando na mais administrativa de todas as Constituições.

Seguindo a "onda" de reformas administrativas, a reforma gerencial no Brasil é implementada durante o Governo de
Fernando Henrique Cardoso, a partir de 1995. Para que a reforma fosse posta em prática, ocorreu a transformação da Secretaria de Administração Federal (SAF) em Ministério da Administração Federal e Reforma do Estado (Mare), órgão responsável pela reforma a ser implantada. Com a nomeação de Luiz Carlos Bresser-Pereira para ministro do Mare, tem início em 1995 a reforma gerencial no Brasil.

Bresser-Pereira (2006a) destaca que a reforma gerencial no Brasil tem dois objetivos. O objetivo de curto prazo é facilitar o ajuste fiscal, e o de médio prazo, tornar a administração pública mais eficiente e moderna, voltada para o atendimento do cidadão. Tendo em vista o alcance desses objetivos, são elaborados 
os dois principais documentos que dão as bases para a reforma: o Plano Diretor da Reforma do Aparelho do Estado e a Emenda Constitucional da Reforma Administrativa. Bresser-Pereira (1998) explica que, para sua elaboração, esses documentos tomam como base as experiências recentes dos países da Organização para a Cooperação e Desenvolvimento Econômico (OCDE), principalmente o Reino Unido, onde a New Public Management teve início.

A principal estratégia da reforma gerencial no Brasil, segundo Bresser-Pereira (1998), era atacar a administração pública burocrática, considerada inflexível e ineficiente. $\mathrm{O}$ autor destaca também a estratégia de fortalecer a capacidade gerencial do Estado, a partir da adoção de formas modernas de gestão. visando se tornar eficiente e democrático. Além disso, outra importante estratégia da reforma era a mudança nas instituições, considerada pelo autor como um mecanismo para fortalecê-las.

Ao caracterizar a reforma que ele mesmo planejou, Bresser-Pereira (2009) afirma que essa pode ser chamada de gerencial por ser inspirada na administração de empresas privadas, visando tornar a administração pública mais eficiente. $\mathrm{O}$ então ministro a caracteriza, também, como democrática, uma vez que, em sua visão, dá as bases para a existência de um regime democrático. Ao denominála também de social-democrática e socialliberal, explica que a primeira pode ser justificada pela existência de um Estado garantidor dos direitos socais, e a segunda, pelo reconhecimento do mercado como ótimo alocador de recursos.

Um dos principais aspectos do modelo proposto por Bresser-Pereira diz respeito aos três setores do Estado moderno e às formas de propriedade que o autor sugere para cada setor, como pode ser observado no quadro 2.

A proposta de Bresser-Pereira (1998), explicitada no quadro abaixo, é de que as diferentes formas de propriedade variem de acordo com o tipo de atividade desempenhada pelo Estado. Sendo assim, no núcleo estratégico, onde são tomadas as decisões estratégicas do Estado, a forma de propriedade deve ser a estatal. O mesmo se dá no caso das atividades que são

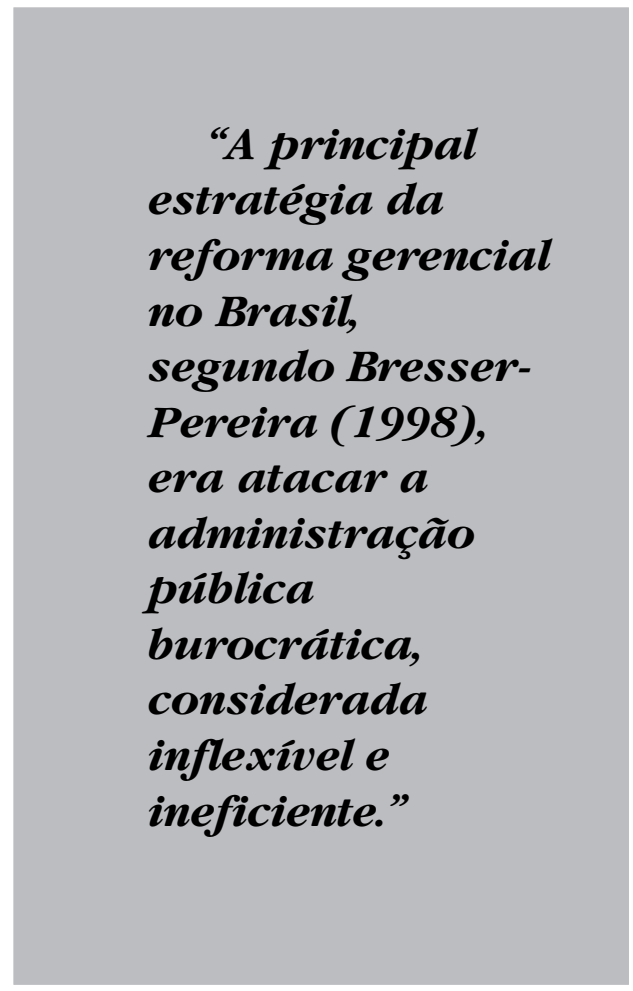

exclusivas do Estado. Entretanto, na visão do autor, as atividades científicas e sociais, que se caracterizam como serviços não exclusivos do Estado, devem ser publicizadas $^{2}$ para as organizações sociais. Estas novas instituições são classificadas como públicas não estatais, porque se dedicam ao interesse público, mas não fazem parte do aparelho de estado. Como 
Quadro 2: Modelos institucionais, formas de propriedade e de administração

\begin{tabular}{|c|c|c|c|c|c|}
\hline \multirow{2}{*}{ Tipo de Organização } & \multicolumn{3}{|c|}{ Forma de Propriedade } & \multicolumn{2}{|c|}{$\begin{array}{l}\text { Forma de } \\
\text { Administração }\end{array}$} \\
\hline & Estatal & $\begin{array}{l}\text { Pública } \\
\text { Não } \\
\text { Estatal }\end{array}$ & Privada & Burocrática & Gerencial \\
\hline $\begin{array}{l}\text { Núcleo Estratégico } \\
\text { Legislativo, Judiciário, } \\
\text { Presidência, Cúpula dos } \\
\text { ministérios }\end{array}$ & & & & & \\
\hline $\begin{array}{l}\text { Atividades Exclusivas } \\
\text { Polícia, regulamentação } \\
\text { fiscalização, fomento, } \\
\text { seguridade social básica }\end{array}$ & & & & & \\
\hline $\begin{array}{l}\text { Serviços Exclusivos } \\
\text { Universidades, hospitai } \\
\text { Centros de pesquisa, m }\end{array}$ & & & & & \\
\hline $\begin{array}{l}\text { Produção para o } \\
\text { Mercado } \\
\text { Empresas estatais }\end{array}$ & Priv & ção & & & \\
\hline
\end{tabular}

Fonte: Adaptado do documento do Ministério da Administração Federal e Reforma do Estado. Plano Diretor da Reforma do Aparelho do Estado. (MARE, 1995, p. 59).

essas atividades envolvem direitos humanos básicos, constituindo-se como atividades de direito privado, mas de propriedade pública, exigem forte financiamento do Estado. É nesse sentido que Bresser-Pereira (1998) defende o processo de publicização, desincentivando a privatização nesses casos. Mas no caso da produção para o mercado, a privatização é sugerida, transferindo-se as atividades das empresas estatais para empresas privadas.

A partir da proposta de formas de propriedades diferentes para distintos setores de atuação do Estado, a reforma gerencial no Brasil também previu novas instituições organizacionais que deveriam ser adotadas. Neste sentido, Bresser-Pereira (1998) propõe a criação de agências reguladoras, que servem para a regulamentação dos setores empresariais não suficientemente competitivos, de agências executivas, que executam as atividades exclusivas do Estado, e de organizações sociais, que atuam no campo dos serviços sociais e científicos atividades não exclusivas do Estado, mas que envolvem direitos humanos básicos -, fazendo parte do setor público não estatal.

Seguindo estas propostas, algumas organizações sociais foram criadas, visando tornar o Estado mais flexível e eficiente. Entre elas, pode-se citar a Casa de Saúde Santa Marcelina do Itaim Paulista, fundada em 1998, em uma parceria com o Governo do Estado de São Paulo, bem como a Rádio Roquette Pinto, criada em 2007, na cidade do Rio de Janeiro, durante o Governo Sérgio Cabral. Entretanto, não houve a expansão ou criação de novas organizações sociais após esse período.

Bresser-Pereira (1998) previu ainda os contratos de gestão, como instrumentos para contratar as novas instituições organizacionais. $\mathrm{O}$ autor explica que, nos contratos de gestão, são previstos os recursos necessários, bem como as metas a serem alcançadas. Rezende (2002a) 
complementa essa ideia, ao afirmar que essas organizações, criadas a partir desse novo modelo de delegação e controle, surgem com o propósito de realizar funções de implementação de políticas públicas, mantendo-se controladas pelas agências centrais a partir de mecanismos de controle de performance, denominados contratos de gestão. Para Bresser, a mudança institucional era a dimensão central da reforma, introduzindo, por meio das novas instituições, um modelo orientado por resultados para os diversos setores burocráticos.

Para tornar ainda mais claro o processo de reforma, Bresser-Pereira explica que essa envolve três dimensões. A primeira dimensão, a institucional, envolve a criação de instituições legais e organizacionais, que viabilizem a gestão. A segunda, a dimensão cultural baseia-se na mudança dos valores burocráticos para os gerenciais, pondo fim ao patrimonialismo. A terceira, a dimensão-gestão, é considerada por Bresser-Pereira (1998) como a mais difícil delas, já que se trata de colocar em prática as novas ideias gerenciais.

Bresser-Pereira (1998) explica que, enquanto a dimensão cultural permeia toda a reforma, a dimensão institucional pode ser representada pela Emenda Constitucional da Reforma Administrativa, e a dimensão-gestão, em um aspecto mais geral, pela estratégia de gestão da qualidade total.

No que diz respeito à Emenda Constitucional da Reforma Administrativa, promulgada em maio de 1998, BresserPereira (1998) destaca sua importância, ao afirmar que ela gerou um grande debate nacional sobre a reforma, que a partir daí ganhou maior apoio. Conforme BresserPereira (2009), o objetivo da emenda era tornar a Constituição de 1988 mais compatível com a reforma. Nesse sentido, a emenda constitucional reformulou o capítulo da administração pública da Constituição de 1988, e promoveu uma profunda mudança institucional, que viabilizou a implementação da reforma (Bresser-Pereira, 1998).

Alguns exemplos de alterações que se deram a partir da emenda constitucional, apresentados por Bresser-Pereira (1998), são: a previsão de mecanismos de flexibilização da estabilidade, a exigência de avaliação para alcançar a estabilidade no fim do estágio probatório, a proibição de aumentos em cascata e o reforço do teto e do subteto de remuneração dos servidores. O autor explica que tais medidas foram adotadas com o objetivo de melhorar a eficiência e a qualidade do serviço público, bem como reduzir seus custos. Neste sentido, a ideia essencial da reforma, conforme Bresser-Pereira (2009), era tornar mais flexível o sistema existente de estabilidade para os servidores públicos, bem como eliminar o Regime Jurídico Único para a contratação de pessoal do Estado.

Com relação à estratégia de gestão para a qualidade total, Bresser-Pereira (1998) apresenta dois programas que a representam. O primeiro deles é o Programa de Qualidade e Participação na Administração Pública (QPAP), criado em 1996, que assume um caráter mais geral, constituindo-se como programa de mudança de uma cultura burocrática para uma cultura gerencial, valorizando a participação e a iniciativa dos servidores. De acordo com os seus objetivos, o QPAP visava à melhoria contínua do desempenho institucional e tinha como meta o aumento da satisfação dos usuários com a administração pública, por meio da consolidação da metodologia de avaliação da gestão pública junto às organizações públicas. 
Embora os objetivos da reforma e do programa QPAP se complementem, eles possuem características diferentes quanto à sua aplicação, conforme observado no quadro 3. Esse programa, ao longo do tempo, tem sofrido algumas modificações. As principais são as seguintes: (i) em 2000, o seu nome mudou para Programa de Qualidade no Serviço Público (PQSP), já que a reforma administrativa tinha, por sua vez, sido extinta, e lhe foi conferida, a partir de então, uma identidade própria; (ii) em 2005, por intermédio do Decreto no 5.378 , de 23 de fevereiro, foi criado o Programa Nacional de Gestão Pública e Desburocratização (GesPública), que resultou da fusão do Programa de Qualidade no Serviço Público e do Programa Nacional de Desburocratização (PrND); (iii), em 2009, o Presidente da República, por meio do Decreto sem número, de 17 de março, instituiu o Ano Nacional da Gestão Pública. Estes marcos, antes de representarem rupturas, constituem avanços importantes a partir $\mathrm{da}$ concepção inicial do referido programa.

O segundo programa da estratégia de gestão para a qualidade total, o Programa de Reestruturação e Qualidade dos Ministérios, é voltado para o auxílio dos ministérios, a fim de que esses promovam a adequação de sua estrutura organizacional de acordo com as diretrizes do Plano Diretor.

Outro importante documento da reforma gerencial brasileira, que se seguiu à emenda constitucional, é o Plano Diretor da Reforma do Aparelho do Estado. O plano apresenta como proposta básica, conforme Bresser-Pereira (2006b), a transformação da administração pública burocrática em gerencial. No documento, inicialmente, é apresentado um diagnóstico do que é chamado de crise da administração pública brasileira, que justifica a necessidade de uma reforma gerencial.
Esse diagnóstico se dá a partir da análise da experiência brasileira de reforma administrativa, que Costa (2008b) descreve como tendo foco nas duas grandes reformas do século passado: a patrimonialista e a burocrática. A partir disso, são estabelecidas as diretrizes da reforma gerencial e são definidas as instituições da administração pública gerencial. Pontos importantes são previstos no plano, como a privatização de empresas estatais, terceirização de atividades de apoio, criação das organizações sociais e demais instituições necessárias à reforma, e o fortalecimento do núcleo estratégico. Além disso, é no Plano Diretor da Reforma do Aparelho do Estado que são definidas as estratégias e as formas de propriedade de cada segmento de atuação do Estado, bem como os objetivos globais e específicos para cada um desses setores de atuação. As três dimensões da reforma, explicitadas anteriormente, também são apresentadas no documento, dando, assim, uma clara visão do que viria a ser a reforma gerencial no Brasil.

Costa (2008a) apresenta os pilares do projeto de reforma, presentes no Plano Diretor, que o autor classifica como: ajuste fiscal duradouro; reformas econômicas orientadas para o mercado; reforma da previdência social; inovação dos instrumentos de política social; reforma do aparelho do Estado.

$\mathrm{Na}$ segunda etapa da reforma gerencial, que se constituiu como a etapa de implementação, houve a criação do Ministério do Planejamento, Orçamento e Gestão, a partir de uma junção do Mare com o Ministério do Planejamento. BresserPereira (1998) explica que a criação desse novo ministério se dá devido a uma crença de que o Mare, sozinho, não teria forças para a implantação da reforma. 
Quadro 3: Características dos programas da reforma do Estado e do QPAP

\begin{tabular}{|l|l|l|}
\hline \multicolumn{1}{|c|}{ Características } & \multicolumn{1}{|c|}{ Reforma do Estado } & \multicolumn{1}{c|}{ QPAP } \\
\hline Fundamentação conceitual & Reengenharia administrativa. & $\begin{array}{l}\text { Melhoria contínua, usando os } \\
\text { conceitos da gestão da qualidade. }\end{array}$ \\
\hline $\begin{array}{l}\text { Natureza da ação para a } \\
\text { implementação }\end{array}$ & $\begin{array}{l}\text { Imposição governamental por meio } \\
\text { de decreto legal, criando agências } \\
\text { executivas, organizações sociais, } \\
\text { empresas. }\end{array}$ & $\begin{array}{l}\text { Voluntária da organizaça por } \\
\text { meio da liderança, não mudando } \\
\text { a natureza jurídica da organização. }\end{array}$ \\
\hline Periodicidade para implementar & Prazo definido para acontecer & Permanente e constante \\
\hline das instituições públicas & $\begin{array}{l}\text { a redução de gastos e a melhoria no no } \\
\text { atendimento. }\end{array}$ & $\begin{array}{l}\text { Longo prazo, buscando a melho- } \\
\text { ria contínua dos resultados } \\
\text { organizacionais, por meio dos } \\
\text { principais indicadores institucio- } \\
\text { nais de gestão. }\end{array}$ \\
\hline Metodologia utilizada & Mudanças constitucionais e legais. & $\begin{array}{l}\text { Modelo de excelência em gestão, } \\
\text { fundamentado pelo Prêmio } \\
\text { Nacional da Qualidade (PNQ). }\end{array}$ \\
\hline Implementação & $\begin{array}{l}\text { Adequar os requisitos legais } \\
\text { impostos e estabelecer um } \\
\text { contrato de gestão. }\end{array}$ & $\begin{array}{l}\text { Pressupõe etapas de sensibiliza- } \\
\text { ção e mobilização para o compro- } \\
\text { metimento, envolvimento e } \\
\text { aplicação do modelo de exce- } \\
\text { lência em gestão. }\end{array}$ \\
\hline
\end{tabular}

Fonte: Elaboração própria, adaptada de Rosenberg (2002)

Assim, o Ministério do Planejamento, Orçamento e Gestão surge com a missão de por em prática a reforma gerencial, cujas diretrizes foram estabelecidas no Plano Diretor da Reforma do Aparelho do Estado. Entretanto, na visão de Bresser-Pereira (1998), esse novo ministério não deu a devida atenção à reforma, e, por isso, não finalizou a sua implementação da forma prevista. Indo ao encontro de Bresser-Pereira, Rezende (2002a) defende que, com a extinção do Mare, o novo ministério que surge altera substancialmente a política de reformas. $\mathrm{O}$ autor explica que poucas entidades previstas na nova matriz institucional foram criadas, mas obteve sucesso na reversão da tendência expansionista dos gastos públicos. Assim, na visão de Rezende (2002a), a reforma teve reduzido resultado em sua dimensão central, que era a mudança institucional, apesar de ter obtido apoio estratégico para o ajuste fiscal. O Mare não conseguiu o mesmo apoio para as políticas de mudança institucional.

No quadro 2, citado anteriormente, dentro do tipo de organização encontram-se aquelas com atividades exclusivas de Estado, cuja função é a de regulamentação. Surge, então, a necessidade de criação das agências reguladoras no Brasil, onde essas, com autoridades independentes de regulação, passam a ser um dos fatos mais inovadores da moderna administração pública brasileira. A criação das agências ocorreu paralelamente ao processo de privatização, surgindo com isso a suposição, inicialmente por parte dos opositores da reforma, de que a existência desse tipo de agência pudesse facilitar ou incentivar a transferência de serviços do setor público para o setor privado, o que na realidade não aconteceu. No quadro 4 estão listadas as agências criadas e pode-se verificar que a maioria surgiu logo após a reforma administrativa.

\section{A reforma gerencial brasileira em análise}

Diante do exposto, pode-se observar que a reforma gerencial tem-se atrelado a um discurso muito positivo, com a 
Quadro 4: Agências reguladoras no Brasil

\begin{tabular}{|c|c|}
\hline Agência reguladora & Instrumento legal \\
\hline Agência Nacional de Energia Elétrica - Aneel & Lei $\mathrm{n}^{0} 9.427$, de 26 de dezembro de 1996 \\
\hline Agência Nacional de Telecomunicaçôes - Anatel & Lei $\mathrm{n}^{0} 9,472$, de 16 de julho de 1997 \\
\hline Agência Nacional do Petróleo - ANP & Lei $\mathrm{n}^{0} 9.478$, de 6 de agosto de 1997 \\
\hline Agência Nacional de Vigilância Sanitária - Anvisa & Lei $\mathrm{n}^{9} 9.782$, de 26 de janeiro de 1999 \\
\hline Agência Nacional de Saúde Suplementar - ANS & 61 , de 28 de janeiro de 2000 \\
\hline Agência Na & de 2000 \\
\hline Agência N & 0 de 2001 \\
\hline $\begin{array}{l}\text { Agência Nacional de Transportes Aquaviários - } \\
\text { Antaq }\end{array}$ & Lei $n^{0} 10.233$, de 5 de junho de 2001 \\
\hline Agência Nacional do Cinema - Ancine & $\begin{array}{l}\text { Medida Provisória } \mathrm{n}^{2} 2.228-1 \text {, de } 6 \text { de } \\
\text { setembro de } 2005\end{array}$ \\
\hline Agência Nacional de Aviaçào Civil - A & Lei $\mathrm{n}^{0} 11.182$, de 27 de setembro de 2005 \\
\hline
\end{tabular}

Fonte: Elaboração própria, adaptada do site do Ministério do Planejamento, Orçamento e Gestão.

proposta de modernização da administração pública, tornando-a mais eficiente. Como envolve uma ideia de progresso, é difícil se contrapor ao modelo gerencial, sem que isso desperte a percepção de ir contra o avanço do País.

Por meio de um olhar mais cuidadoso, a reforma gerencial da administração pública brasileira deixa transparecer algumas vulnerabilidades, no que diz respeito, inclusive, aos seus propósitos principais. Embora surja com o objetivo de substituir o modelo burocrático de administração pública, fortemente criticado por sua rigidez e ineficiência, o modelo gerencial ainda apresenta características do modelo burocrático, como a profissionalização e a dominação burocrática, não havendo, assim, um verdadeiro rompimento com o modelo anterior. Paes de Paula (2005a) mostra que se tem hoje uma "burocracia flexível", com características burocráticas que apenas são adaptadas às necessidades de flexibilização. Neste sentido, Paes de Paula (2005a, p. 144) mostra contradições no discurso do próprio idealizador da reforma, ao afirmar que "embora critique a burocracia, diversas vezes Bresser-Pereira aponta a importância da existência de uma burocracia pública capaz de controlar o processo decisório e assegurar a eficiência administrativa".

Nem mesmo o patrimonialismo pode ser considerado como modelo completamente superado na administração pública brasileira. Na visão de Paes de Paula (2005a), o patrimonialismo não foi superado a partir da reforma gerencial, pois " a simples condenação das práticas patrimonialistas e a adesão à visão gerencialista não bastam para uma mudança na cultura política” (PAes De Paula, 2005a, p. 141). Indo ao encontro de Paes de Paula (2005a), Lima Junior (1998) defende que nunca houve no Brasil modelo de administração pública plenamente instalado, encontrandose, na verdade, modelos incompletos e superpostos.

O fato de a reforma gerencial não ter sido concluída no País também gera outras preocupações. Como o Brasil apresenta histórico de vários modelos de administração incompletos, que se superpõem, a presença do patrimonialismo e da rigidez burocrática na administração pública brasileira atual gera resistência à mudança. Assim, como mostrou Lima Junior (1998), o processo de reforma gerencial não se trata simplesmente de substituir um modelo por outro, dando-se de forma muito mais complexa. 
Nesse sentido, para a consolidação da reforma gerencial, é preciso que as reformas administrativas que a antecederam estabeleçam as bases para tal. Embora exista a condição legal para a implementação da administração gerencial, existem fatos históricos que sugerem que o Brasil ainda não apresenta condições para tanto. O primeiro se refere à desconfiguração do modelo burocrático pela transformação dos cargos públicos em favoritismo político. Em seguida, juntou-se à administração direta de forma caótica enorme setor empresarial (empresas públicas), autárquico (autarquias) e fundacional (fundações públicas), que fugiu ao controle central, pela multiplicação dos órgãos e empresas com alto grau de autonomia de contratação nos anos 1980, trazendo consequentemente os interesses privados para dentro da administração pública. Esta, por último, sofreu o impacto da desorganizada e malsucedida reforma realizada na era do Governo Collor. A administração pública brasileira não tem visão holística dos seus problemas e evoluiu de forma descontínua do patrimonialismo para o modelo burocrático, com resultados heterogêneos, tornando a questão complexa e não podendo ser vista de forma planejada. Dessa forma, é importante examinar os diversos processos de reforma administrativa no Brasil, para melhor compreensão do momento atual da administração pública.

Ao caracterizar a reforma como gerencial, Bresser-Pereira (2009) explica que essa se baseia nas práticas de empresas privadas, para que se torne mais eficiente. Entretanto, ao seguir tal lógica, a administração pública acaba por se preocupar com a eficiência técnica, e a democratização e o interesse público perdem espaço, como defende Paes de Paula (2005a). Posto que a administração privada esteja predominantemente voltada para resultados, a sua transposição para a administração pública faz com que esta seja orientada por uma lógica de eficiência econômica, afastando-a do seu objetivo primeiro: a busca do bem comum.

Bresser-Pereira (2009) também caracteriza a administração pública gerencial

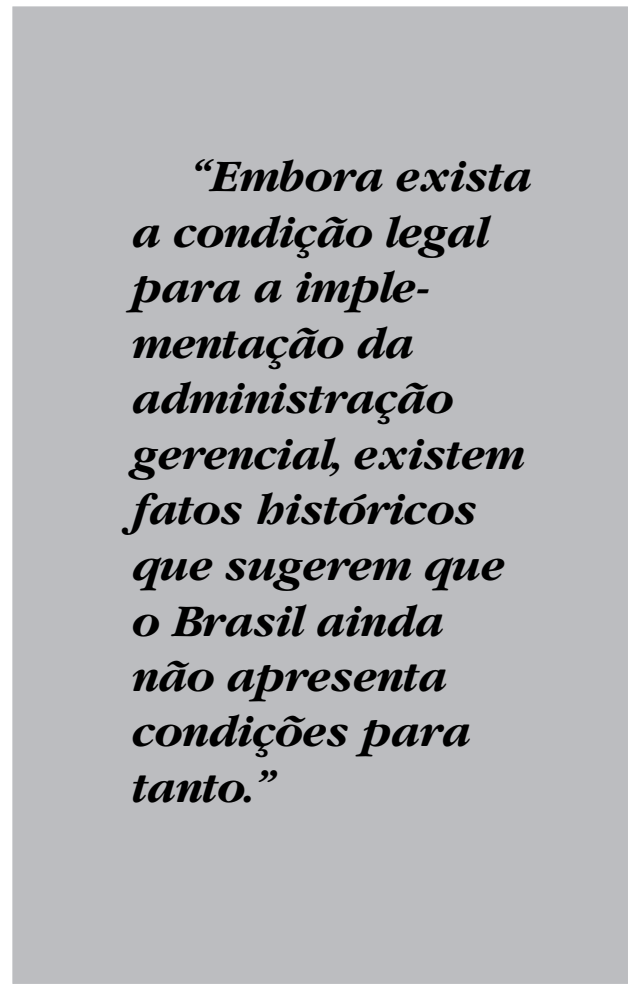

como democrática, já que, na visão do autor, prevê a existência de um regime democrático. Entretanto, mecanismos de participação ou controle social não são previstos na reforma, e as características centralizadoras e autoritárias dos modelos anteriores são mantidas. Como mostrou Paes de Paula (2005a), a relação entre Estado e sociedade não é suficientemente discutida, para que possa ser considerada modelo que segue uma democracia plena. 
Embora Bresser-Pereira (2009) destaque como uma das principais características do modelo gerencial o fato de se constituir como modelo democrático, Paes de Paula (2005a) argumenta que ele mantém o autoritarismo, pois o processo decisório permanece como monopólio do núcleo estratégico e das instâncias executivas. $\mathrm{Na}$ visão da autora, a nova estrutura do Estado, após a reforma, não conseguiu garantir "uma inserção da sociedade civil nas decisões estratégicas e na formulação de políticas públicas" (PAES DE Paula, 2005a, p. 141). Não foi possível a infiltração das demandas populares, a partir da nova estrutura do Estado que se consolidou após a reforma, como mostrou Paes de Paula. Apesar de haver um discurso participativo na proposta de reforma gerencial, "na prática se enfatiza o engajamento da própria burocracia pública ou dos quadros das organizações sociais no processo de gestão" (PAes de Paula, 2005a, p. 147). Indo ao encontro de Paes de Paula, Martins (1997, p. 71) afirma que "parece haver um hiato entre o sistema político-representativo e os imperativos de modernização da burocracia pública". Assim, a concepção de democracia da administração pública gerencial parece ser limitada. No quadro 5, estão relacionadas algumas falhas da implantação e aspectos positivos da Reforma de 1995, em que se destaca a busca por melhor atendimento ao cidadão, com redução dos gastos públicos.

Uma das principais estratégias da reforma, como visto anteriormente, é a mudança nas instituições. Prevista na Emenda Constitucional da Reforma Administrativa, tal mudança se dá por meio da criação de novas instituições, como as agências reguladoras, as agências executivas e as organizações sociais, descritas acima. Ainda que a mudança institucional seja considerada uma das principais dimensões da reforma, e que essa tenha sido muito bem definida no Plano Diretor, ela não foi totalmente implantada. Assim, há uma fragmentação do aparelho do Estado, com a convivência de formas organizacionais antigas e novas (PAes de Paula, 2005a). Além de sua implementação não ser tão simples quanto parece inicialmente, a reforma gerencial brasileira apresenta vulnerabilidades associadas às suas características mais básicas. A busca de uma administração pública mais eficiente pode trazer sérias consequências para a sociedade, como a excessiva ênfase em questões de âmbito econômico e a negligência de questões de âmbito social, deixando em segundo plano aquilo que de fato é importante para a sociedade e servindo de obstáculo para o alcance do bem comum. Entretanto, vale ressaltar que mudanças positivas também ocorreram como consequência do processo de reforma.

\section{Conclusões}

Sempre em busca de um melhor modelo de administração pública para o País, foram vividas, nos últimos séculos, transformações denominadas de reformas administrativas, que alteraram o funcionamento do aparelho do Estado. Entretanto, a passagem do modelo patrimonial para o burocrático, e deste para o modelo gerencial, não se deu de forma tão linear e clara quanto parece à primeira vista. Os modelos de administração pública no Brasil acabaram se sobrepondo, trazendo limitações ao seu bom funcionamento. Dentro desse contexto, o presente estudo buscou identificar as vulnerabilidades presentes no processo de reforma gerencial no Brasil.

A partir dessas reflexões, pode-se concluir que o modelo gerencial, adotado 


\section{Quadro 5: Características da reforma de 1995}

\begin{tabular}{|c|c|}
\hline Principais causas da falha da reforma de 1995 & Principais pontos positivos da reforma de 1995 \\
\hline $\begin{array}{l}\text { 1- Diferenciaçào entre os objetivos da Secretaria de } \\
\text { Recursos Humanos (SRH) e da Secretaria de Reforma } \\
\text { do Estado (SER) levou à extinçào do Mare. }\end{array}$ & $\begin{array}{l}\text { 1- Criação de diversas agências reguladoras para } \\
\text { controle e fiscalização de diversos setores. }\end{array}$ \\
\hline $\begin{array}{l}\text { 2- Dificuldade de enquadramento das organizaçôes } \\
\text { públicas à nova estrutura organizacional designada } \\
\text { pelo Estado, devido à dualidade na prestaçào dos } \\
\text { serviços de uma mesma organizaçào, ora relacionados } \\
\text { à atividade exclusiva do Estado, ora nào. }\end{array}$ & $\begin{array}{l}\text { 2- Criaçào de diversas organizaçồes sociais sem fins } \\
\text { lucrativos. }\end{array}$ \\
\hline $\begin{array}{l}\text { 3- Resistência das organizaçōes públicas a mudarem a sua } \\
\text { funçào dentro do Estado, devido às possiveis reduçôes } \\
\text { orçamentárias e aos riscos inerentes de terem que buscar } \\
\text { a auto sustentabilidade. }\end{array}$ & $\begin{array}{l}\text { 3- Avaliação por desempenho dos servidores } \\
\text { públicos e criaçâo de novas carreiras dentro da } \\
\text { administraçâo pública. }\end{array}$ \\
\hline $\begin{array}{l}\text { 4- Resistência sindical dos servidores públicos contra a } \\
\text { reforma do Estado, }\end{array}$ & $\begin{array}{l}\text { 4- Estabelecimento dó contrato de gestão para } \\
\text { algumas organizaçồes. }\end{array}$ \\
\hline $\begin{array}{l}\text { 5- Falta de consenso sobre o significado de performance. } \\
\text { Para as agências de controle, o conceito está relacionado } \\
\text { ao cumprimento das regras e dos controles; enquanto } \\
\text { que, para à demais organizaçōes, o desempenho está } \\
\text { relacionado à garantia de recursos destinados à sua } \\
\text { sobrevivência e à execuçào das metas pactuadas. }\end{array}$ & $\begin{array}{l}\text { 5- Criaçào de diversos programas governamentais } \\
\text { com o intuito de melhorar a gestão pública. } \\
\text { Exemplo: Programa Nacional de Gestão Pública e } \\
\text { Desburocratização (GesPública). }\end{array}$ \\
\hline $\begin{array}{l}\text { 6- Falta de autoridade legal para implementar as mudanças } \\
\text { determinadas por lei, o que leva a um longo processo de } \\
\text { negociaçào, reduzindo as possibilidades de alcançar os } \\
\text { objetivos pretendidos pela reforma. }\end{array}$ & $\begin{array}{l}\text { 6- Cooperação dos órgàos públicos, buscando } \\
\text { reduzir os seus orçamentos e gastos. }\end{array}$ \\
\hline $\begin{array}{l}\text { 7- Resistência à mudança imposta pela reforma, devido ao } \\
\text { receio da perda de poder político mediante às novas regras } \\
\text { impostas e à nova conffiguraçào da estrutura organizacional. }\end{array}$ & $\begin{array}{l}\text { 7- Elaboraçào de diversas açôes de desburocrati- } \\
\text { zaçâo nas instituiçòes, simplificando os processos. }\end{array}$ \\
\hline $\begin{array}{l}\text { 8- Desinteresse do governo petista em continuar com a } \\
\text { reforma, que buscava dar maior autonomia às instituições } \\
\text { públicas com mais responsabilidade, de forma a descen- } \\
\text { tralizar a organizaça estatal e buscar o controle por } \\
\text { resultados, em vez da fiscalização direta. }\end{array}$ & $\begin{array}{l}\text { 8- Criação de novas formas de atender e ouvir o } \\
\text { cidadão, a exemplo das ouvidorias institucionais. }\end{array}$ \\
\hline
\end{tabular}

Fonte: Elaboração própria, adaptada de Rezende (2004b)

pela administração pública brasileira a partir de sua reforma mais recente, ainda mantém características patrimonialistas e, principalmente, burocráticas dos modelos anteriores. Mas além dos problemas trazidos por essa sobreposição, o modelo gerencial possui vulnerabilidades inerentes ao próprio paradigma, como o foco na eficiência econômica, que o desvia de sua função social, bem como a ausência de uma democracia plena, com a manutenção dos processos decisórios centralizados no núcleo estratégico do governo.

Pode-se concluir, ainda, que a reforma do Estado, proposta em 1995, em seu pleito amplo, não foi concluída por diversos motivos, desde a falta de autori- dade para impô-la a todos os setores da administração pública, até o embate entre o controle requerido pelas agências fiscalizadoras e a busca do desempenho exigida pela própria reforma. Esta, entretanto, trouxe vários pontos efetivos para a sociedade brasileira, pois despertou a preocupação dos órgãos públicos de promoverem melhor atendimento para o cidadão, usuário dos seus serviços. As inovações trazidas pela reforma, como a criação das agências reguladoras, também merecem destaque.

Ainda que haja críticas ao modelo gerencial por suas vulnerabilidades citadas ao longo do artigo, não existe hoje uma proposta de reforma bem definida, que 
traga um novo modelo de administração pública capaz de solucionar os problemas atuais. Entretanto, as mudanças em termos de maior orientação para a sociedade são urgentes.

Fortemente preocupado com a eficiência econômica, o modelo gerencial não mantém seu foco na sociedade. A função social da administração pública torna-se, assim, secundária. É nesse sentido que mudanças urgentes em termos de ampliação do processo democrático são demandadas, com maior participação e controle social, bem como maior orientação para o atendimento das demandas da sociedade. A preocupação com a eficiência econômica não deve ser dispensada, mas relegada a um papel secundário na administração pública brasileira, sendo tratada como meio e não como fim.

Como o objetivo da administração pública é a busca do bem comum, ela precisa alterar o seu foco para que cumpra sua função social. Os aspectos positivos trazidos pela reforma gerencial devem, assim, ser conciliados com mudanças nesse sentido, somando essas características ao contínuo processo de construção de uma nova administração pública brasileira.

(Artigo recebido em março de 2012. Versão final em julho de 2012).

\section{Notas}

1 Legenda: Dentro do contexto constitucional, é possível verificar a evolução de como se deu a centralização das regras que regem a administração pública, como segue: a Constituição do Império, de 1824, nada dispunha sobre administração pública; a primeira Constituição republicana, promulgada em 1891, só tinha dois artigos; a Constituição de 1934 possuía sete artigos; a Constituição de 1946, que redemocratizou o País, tinha 11 artigos; a Constituição de 1967, com seu viés autoritário e concentrador de poder, não passou de 21 artigos; e, finalmente, a Constituição de 1988 alcançou 65 dispositivos sobre administração pública, sendo a mais normativa, comparada com outros países (MOREIRA NeTO, 1999).

2 A palavra publicização foi criada pelo governo para distinguir a propriedade pública não estatal da propriedade pública, bem como da propriedade privada. A publicização pressupõe a extinção de órgãos ou entidades estatais e subsequente absorção de suas atividades por organizações sociais. O processo de publicização busca assegurar o caráter público e o direito privado da nova entidade, assegurando-lhe, assim, maior autonomia administrativa e financeira. As organizações sociais são organizações públicas não estatais, mais especificamente fundações de direito privado que celebram contrato de gestão com o Poder Executivo, com aprovação do Poder Legislativo, ganhando o direito de fazer parte do orçamento público federal, estadual ou municipal. (Petrucci e Schwartz, 1999, p. 46-48). 


\section{Referências}

BARZELAY, M. The new public management: improving research and policy dialogue. University of California Press/ Russel Sage Foundation, 2001.

Bresser Pereira, L. C. Do Estado patrimonial ao gerencial. In: Sachs, I.; Wilheim, J.; Pinheiro, P. S. (Orgs.). Brasil: um século de transformações. São Paulo: Companhia das Letras, 2001.

. Construindo o Estado republicano: democracia e reforma da gestão pública. Rio de Janeiro: FGV, 2009.

- Reforma da nova gestão pública: agora na agenda da América Latina, no entanto.... Revista do Serviço Público, Brasília, Ano 53, nº 1, p.5-27, jan./mar. 2002.

. Reforma do Estado para a cidadania. São Paulo: Editora 34, 1998.

. Da administração pública burocrática à gerencial. In: BRESSER-PEREIRA,

L. C.; SPINK, P. Reforma do Estado e administração pública gerencial. $7^{\mathrm{a}}$ ed. Rio de Janeiro: FGV, 2006a.

. Gestão do setor público: estratégia e estrutura para um novo Estado. In: Bresser-Pereira, L. C.; SPINK, P. Reforma do Estado e administração pública gerencial. $7^{a}$ ed. Rio de Janeiro: FGV, 2006b.

Centro latino-Americano de Administração para o Desenvolvimento/clad. Uma nova gestão pública para a América Latina. Revista do Serviço Público, Brasília, Ano 50, n 1 , p. 121-144, jan./mar. 1998.

Costa, F. L. Brasil: 200 anos de Estado; 200 anos de administração pública. Revista de Administração Pública, Rio de Janeiro , v. 42, nº 5, p. 829-74, 2008a.

. História das reformas administrativas no Brasil: narrativas, teorizações e representações. Revista do Serviço Público, Brasília, v. 59, no 3, p. 271-288, jul./set. 2008b. Fleury, S. Reforma del Estado. Revista de Administração Pública, Rio de Janeiro, v. 35, n 5, p. 7-48, set./out. 2001.

KETTL, D. F. The global public management revolution: a report on the transformation of governance. Washington: Brookings Institution Press, 2000.

Lima Junior, O. B. As reformas administrativas no Brasil: modelos sucessos e fracasso. Revista do Serviço Público, Brasília, Ano 49, nº 2, p. 5-32, abr./jun. 1998.

Macedo, E. M.; Alves, A. M. Reforma administrativa: o caso do Reino Unido. Revista do Serviço Público, Brasília, Ano 48, no 3, p. 62-83, set./dez. 1997.

Marcelino, G. F. Governo, imagem e sociedade. Brasília: Fundação Centro de Formação do Servidor Público - FUNCEP, 1988.

Martins, H. F. Burocracia e a revolução gerencial - a persistência da dicotomia entre política e administração. Revista do Serviço Público, Brasília, Ano 48, no 1, p. 42-78, jan./ abr. 1997.

Ministério da Administração Federal e Reforma do Estado (MARE). Plano Diretor da Reforma do Aparelho do Estado. Brasília: MARE, 1995. 
Modesto, P. E. G. Reforma administrativa e marco legal das organizações sociais no Brasil: as dúvidas dos juristas sobre o modelo das organizações sociais. Revista do Serviço Público, Brasília, Ano 48, n 2, p. 27-57, maio/ago. 1997.

Moreira Neto, D. de F. Apontamentos sobre a reforma administrativa: emenda constitucional $\mathrm{n}^{\circ}$ 19, de 4 de junho de 1998. Rio de Janeiro: Renovar, 1999.

Osborne, D.; Gaebler, T. Reinventando o governo. 2a ed. Brasília: MH Comunicação, 1994. Ormond, D.; Löffler, E. A nova gerência pública. Revista do Serviço Público, Brasília, Ano 50, n 2, p. 67-96, abr./jun. 1999.

PAGE, S. What's new about the new public management? Administrative change in the human services. Public Administration Review, Lindblom, v. 65, n 6, p. 713-727, nov./ dec. 2005.

Paes de Paula, A. P. Por uma nova gestão pública: limites e potencialidades da experiência contemporânea. Rio de Janeiro: FGV, 2005b.

Paes de Paula, A. P. Administração pública brasileira entre o gerencialismo e a gestão social. Revista de Administração de Empresas, RAE, São Paulo, v. 45, nº 1, p. 36-49, jan./ mar. 2005a.

Petrucci, V.; Schwartz, L. Administração Pública Gerencial: a reforma de 1995: ensaios sobre a reforma administrativa brasileira no limiar do século XXI. Brasília: ENAP, 1999. PollitT, C. Antistatist reforms and new administrative directions: public administration in the United Kingdom. Public Administration Review, Lindblom, v. 56, n 1, p. 81-87, jan./ feb. 1996.

REZENDE, F. C. O dilema do controle e a falha seqüencial nas reformas gerenciais. Revista do Serviço Público, Brasília, Ano 53, n³, p. 50-74, jul./set. 2002a.

REZENDE, F. C. Por que Falham as Reformas Administrativas? Rio de Janeiro: EDITORA FGV, 2004b.

Rosenberg, G. Desempenho Global da Fundação Oswaldo Cruz: um Instrumento de Autoavaliação. 2002. 241 f. Dissertação (Mestrado em Tecnologia de Processos Químicos e Bioquímicos) - Universidade Federal do Rio de Janeiro, Rio de Janeiro, 2002.

SCHWARTZMAN, S. Nota sobre o patrimonialismo e a dimensão pública na formação da América Latina contemporânea. (12/10/2006). Disponível em: < http:/ / www.schwartzman.org.br/ simon/patrimonialismo06.pdf>. Acesso em: 8 set. 2010.

SECCHI, L. Modelos organizacionais e reformas da administração pública. Revista de Administração Pública, Rio de Janeiro, v. 43, n 2, p. 347 - 69, mar./abr., 2009.

WEBER, M. Economia e sociedade: fundamentos da sociologia compreensiva. $4^{\mathrm{a}}$ ed. Brasília: Universidade de Brasília, 2009. 


\section{Resumo - Resumen - Abstract}

\section{A reforma gerencial brasileira em questão: contribuições para um projeto em construção} Vanessa Brulon; Pierre Ohayon e Gerson Rosenberg

Mudanças no cenário internacional, avanços dos meios de informação e inovação tecnológica colocam as instituições públicas frente a grandes desafios. Neste sentido, foi instaurado por meio legal o processo da Reforma do Estado e da Administração Pública no Brasil, em 1995. O modelo propôs a transferência de práticas das empresas privadas para o setor público, em busca de uma administração gerencial. O presente artigo resulta de uma reflexão acerca do processo de implementação da reforma do Estado e das suas consequências na administração pública brasileira. Assim, tem por objetivo identificar as possíveis vulnerabilidades presentes no processo de reforma gerencial brasileiro. Este trabalho finaliza apontando algumas causas que levaram ao descrédito da reforma por parte das instituições pública brasileiras, como a dificuldade das organizações públicas de se ajustarem à nova estrutura organizacional designada pelo Estado, a resistência à mudança imposta pela reforma, bem como alguns pontos positivos provenientes dessa, entre os quais se pode destacar a criação de diversos programas governamentais com o intuito de melhorar a gestão pública ou a cooperação dos órgãos públicos a fim de reduzir os seus orçamentos e gastos.

Palavras-chave: Reforma gerencial; Administração pública; Brasil

\section{La reforma gerencial brasileña en debate: contribuciones para un proyecto en construcción}

Vanessa Brulon; Pierre Obayon y Gerson Rosenberg

Los cambios en el ámbito internacional, los avances en la tecnología de los medios de comunicación y innovación tecnológica plantean grandes desafios a los cuales se enfrentan las instituciones públicas. En este sentido, se estableció legalmente el proceso de Reforma del Estado y Administración Pública en Brasil, en 1995. Con este fin, propuso la transferencia de las prácticas privadas para el sector público en busca de una administración gerencial. Este artículo resulta de una reflexión acerca del proceso de implementación de la reforma del Estado y sus consecuencias para la administración pública brasileña. De forma que tiene como objetivo identificar posibles vulnerabilidades presentes en el proceso de reforma de la gestión en Brasil. Se concluye señalando algunas de las causas que condujeron al desprestigio de la reforma de las instituciones públicas brasileñas, tales como la dificultad de las organizaciones públicas de adaptarse a la nueva estructura organizativa designada por el Estado, la resistencia al cambio impuesto por la reforma, así como algunos buenos puntos, entre los cuales podemos destacar la creación de diversos programas de gobierno destinados a mejorar la cooperación dela administración pública o de los organismos públicos a fin de reducir sus presupuestos y gastos.

Palabras clave: Reforma gerencial; Administración pública; Brasil.

\section{The Brazilian managerial reform in question: contributions to a project under construction \\ Vanessa Brulon; Pierre Ohayon and Gerson Rosenberg}

Changes in the international arena, advances in technology and innovation pose public institutions facing great challenges. In this sense, was established by law the process of State and public administration Reform in Brazil, in 1995. To this end, proposed the transfer of private practices for the public sector in search of a management administration. This article results 
from a reflection of the implementation process of state reform and its consequences for the Brazilian public administration. In this sense, aims to identify potential vulnerabilities present in the process of management reform in Brazil. It concludes by stating some causes that led to the discrediting of the reform by the brazilian public institutions such as the difficulty of public organizations to adjust to the new organizational structure designated by the State, resistance to change imposed by the reform, as well as some good points, among which we can highlight the creation of various government programs aimed at improving the cooperation of public management or public agencies to reduce their budgets and spending.

Keywords: Administrative reform; Public administration; Brazil

Vanessa Brulon

Mestre em administração pública e doutoranda em administração pela Escola Brasileira de Administração Pública e de Empresas (EBAPE/FGV). E-mail: vanessabrulon@gmail.com

Pierre Ohayon

Doutor em administração de empresas pela Faculdade de Engenharia e Arquitetura (FEA/USP). É professor associado II da Faculdade de Administração e Ciências Contábeis (FACC/UFRJ). E-mail: pohayon@facc.ufrj.br

Gerson Rosenberg

Doutor em Tecnologia de Processos Químicos e Bioquímicos pelo Instituto Alberto Luiz Alberto Coimbra de Pósgraduação e Pesquisa de Engenharia (COPPE/UFRJ). Atua como tecnologista em Saúde Pública da Fundação Oswaldo Cruz Fiocruz. E-mail: gerson@fiocruz.br 